\title{
Recognizing and Breaking the Cycle of Trauma and Violence Among Resettled Refugees
}

\author{
Meilynn Shi ${ }^{1} \cdot$ Anne Stey $^{2} \cdot$ Leah C. Tatebe ${ }^{3}$
}

Accepted: 21 September 2021 / Published online: 13 November 2021

(c) The Author(s), under exclusive licence to Springer Nature Switzerland AG 2021

\begin{abstract}
Purpose of Review The number of refugees across the globe continues to grow, leaving a large proportion of the global population in a vulnerable state of health. However, the number of robust clinical interventions has not kept apace. This paper provides a general review of literature on the trauma and violence that refugees face, the impact on health outcomes, and some of the promising models for clinical intervention.

Recent Findings Refugees experience a cycle of trauma, violence, and distress that begins before migration and continues during migration and after resettlement. It has been challenging to develop robust clinical interventions due to the cumulative and cyclic effects of trauma, as well as the unique experiences of trauma that each refugee community and each refugee individual faces.

Summary Trauma-informed care is a critical component of health care. Developing stronger guidelines for trauma-informed care will help clinicians better provide inclusive and equitable care for refugee patients.
\end{abstract}

Keywords Refugees $\cdot$ Violence $\cdot$ Trauma $\cdot$ Trauma-Informed Care $\cdot$ Community partnerships $\cdot$ Resiliency

\section{Introduction}

At the end of 2019, more than 79 million people across the globe were forcibly displaced due to war, persecution, or violent conflict [1]. This included more than 20 million refugees, forced to flee their country and unable to return in fear of persecution $[1,2]$. Since the enactment of the Refugee Act of 1980, the United States (U.S.) has accepted more than 3.8 million refugees and asylees, and in recent years, the U.S. has received some of the largest numbers of asylum applications worldwide [1, 3]. There

This article is part of the Topical Collection on Intentional Violence

Leah C. Tatebe

Leah.Tatebe@cookcountyhhs.org

1 Feinberg School of Medicine, Northwestern University, Chicago, IL, USA

2 Division of Trauma, Acute Care Surgery, and Surgical Critical Care, Feinberg School of Medicine, Northwestern University, Chicago, IL, USA

3 Department of Trauma and Burn Surgery, Cook County Health, Rush University, 1950 W Polk St, Chicago, IL 60612, USA have also been proposals to raise the annual federal refugee admission ceiling from 15,000 in FY2021 to as high as 125,000 in FY2022 [4].

However, despite an increasing visibility of refugees in academic and political discourse, refugees remain some of the most vulnerable public health populations. Refugees face a "triple burden" of infectious diseases, mental health disorders, and non-communicable diseases, compounded by an additional triple burden of exposures to trauma before, during, and after migration - a defined risk factor for poor long-term health outcomes [5, 6]. Studies have shown that refugees experience more types of trauma compared to American-born individuals and other immigrants, develop post-traumatic stress disorder (PTSD) at higher rates compared to other immigrants and Vietnam war veterans, and experience higher rates of chronic disease compared to other immigrants [7, 8•, 9, 10]. Refugees are also at an overall higher risk of adverse health outcomes due to the structural barriers they face in host countries $[9,11 \bullet \bullet]$.

Even though the refugee population continues to grow and continues to be recognized as a vulnerable population, there is still little guidance on how clinicians can best meet the needs of refugees [12]. Developing robust and agile 
clinical interventions has been challenging not only due to language barriers and cultural differences, but also due to the unique forms of trauma and violence that each refugee community and each refugee individual faces. In 2019, the largest proportion of refugee arrivals in the U.S. came from the Democratic Republic of Congo, Burma, and Ukraine [13]. The past decade has been marked by crises in Syria, South Sudan, Venezuela, Ethiopia, Yemen, and many more, in addition to renewed conflicts in Afghanistan, Iraq, Libya, and Somalia [1]. No single clinical intervention or approach is likely to address such a wide and dynamic spectrum of needs.

Nevertheless, it remains clear that establishing traumainformed interventions for refugees and refugee communities is critical for improving health outcomes, increasing health care access and equity, and potentially reducing health care costs. This includes building structurally competent tools for assessing trauma, developing interdisciplinary models for care, and creating an inclusive health care environment that welcomes refugees and recognizes them for their strengths and resiliency $[14 \bullet, 15]$. Studies have also shown that the risk and severity of PTSD can be decreased if refugees are connected with mental health services immediately upon arrival $[8 \bullet, 16 \bullet \bullet$. This highlights the importance of integrating refugees into a coordinated system of care early on, an area in which physicians and healthcare professionals can play an important role. This paper summarizes some of the recent literature on approaches to understanding and addressing the trauma and violence that refugees experience.

\section{Pre-migration Trauma}

Much of the early literature has focused on forms of trauma that refugees face prior to migration. Over the past few decades, various cross-cultural instruments have been developed to assess refugees for histories of trauma and for symptoms associated with PTSD [17]. These instruments incorporate not only translations for linguistic equivalence, but also cultural expressions and understandings of trauma, distress, and mental health [17]. The Harvard Trauma Questionnaire (HTQ), one of the most commonly used checklists, was initially developed in the 1990s to evaluate trauma and PTSD in refugees from Vietnam, Cambodia, and Laos [18]. The first section of the questionnaire asks about 17 traumatic experiences, including lack of food or water, ill-health without access to medical care, forced separation from family members, brainwashing, and murder of a family or friend [18]. The HTQ has since been adapted for different populations and studies [17]. Developing sensitive and specific tools that can be easily and routinely administered remains a key challenge. The Refugee Health Screener-15 (RHS-15), for example, was designed more recently to help clinicians screen for common mental health disorders more efficiently [19].

These tools have been important in revealing the strong predictive value of trauma for PTSD, depression, and anxiety $[20,21]$. Among Congolese refugees, some of the experiences highly correlated with developing PTSD include rape, witnessing murder, and seeing people carry dead or mutilated bodies [22]. Among Rohingya refugees, some of the most common traumatic events involve torture, beating, confiscation or destruction of property, extortion, or robbery, and being forced to hide [23, 24]. Women and children are especially vulnerable groups. Women are subject to higher rates of PTSD, in part due to higher rates of sexual and gender-based violence, such as rape, intimate partner violence, dowry killing, female genital mutilation/cutting, and forced prostitution [22, 23, 25-28]. Children are at higher risk of poorer developmental and long-term health outcomes, in part because childhood exposure to trauma, especially to intrafamilial and extrafamilial violence, can be more damaging than exposure to trauma as an adult [29-31]. For some refugee groups, the indirect act of witnessing trauma is linked to higher rates of PTSD than the direct act of experiencing trauma, highlighting the different ways that trauma affects individuals [32].

Refugees experience many types of trauma, and the number of traumatic events is linked to higher rates of mental health disorders. [33, 34••] Past exposure to trauma and violence also places refugees at a higher risk of exposure

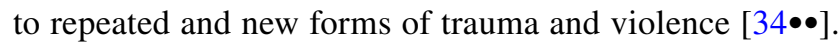
These histories of trauma play a key role in understanding refugee health, but they are only one part.

\section{Migration Trauma}

Many of these forms of trauma only continue during migration, with some studies arguing that refugees are even more vulnerable to insult and injury during the migratory process [5, 25]. Rohingya refugees fleeing to Malaysia, for instance, will either travel overland for months through Thailand's jungles, which are now littered with hundreds of gravesites, or risk the travel overseas in small, cramped boats across the Bay of Bengal and the Andaman Sea [24]. Such journeys place them at constant risk of dying from sickness or starvation, being tortured or killed by smugglers, or drowning at sea, among other life-threatening dangers [24].

While making these journeys, and later while staying in refugee settlements, women are at an especially high risk of sexual and gender-based violence [26]. Studies have reported that South Sudanese refugees in Uganda experience 
higher rates of domestic violence and Somali refugees in Kenya experience high rates of intimate partner violence while staying in refugee camps $[35,36]$. Many young girls are abducted from refugee camps to be forced into marriage or to be sold for dowries, and many women are raped or beaten by camp security themselves [35, 37].

States of conflict and upheaval generally leave women vulnerable to forced marriage, sexual exploitation, sexual slavery, and human trafficking [38]. They also leave refugee children and unaccompanied minors vulnerable to abuse, violence, and human trafficking [39•, 40]. Crowded housing can place children at increased risk of physical and sexual abuse, and resource constraints, such as a lack of firewood, can place children at further risk by forcing them to venture away from camp in search of fuel [40]. Childhood trauma and refugee status and violence are also considered risk factors for human trafficking during migration and even after resettlement [41 •]. However, incidences of human trafficking are often difficult to report and under-reported, complicating political action and clinical intervention [41 $\bullet, 42]$.

Some studies have also found that the risk of PTSD and mental health disorders, as well as the risk of substance use disorders, increases the longer refugees stay in refugee camps [43-45]. These are concerning findings when refugees are spending years living in "temporary" settlements, with lack of clean water, lack of food and nutrition, lack of sufficient shelter, lack of proper infectious disease control, lack of adequate health services, and more-all of which keep refugees in a chronic state of violence, trauma, and deprivation $[23,35,46]$.

It is thus important that refugees are properly screened for trauma and mental health upon arrival and resettlement in the U.S. Early linkage to mental health services has been shown to improve mental health outcomes, and some studies have even suggested that there may be a critical period following trauma exposure, after which it may be too late

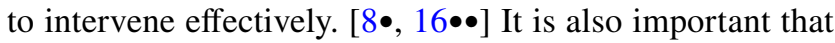
refugees continue to receive the proper health screening and services because experiences of distress, violence, and trauma do not end upon resettlement.

\section{Post-migration Trauma}

A growing amount of literature has been focusing on forms of violence and distress that continue and arise after migration and during resettlement. In the U.S., many refugee groups continue to face barriers due to racial and ethnic discrimination, restrictive immigration policies, limited English proficiency, limited social support, and economic insecurity, leaving many with limited options for employment, education, affordable housing, health care insurance, and other opportunities [9, 47-50]. Accessing health care services can be particularly challenging due to barriers in transportation, translation, and cost, exacerbating the existing effects of trauma on increased risk of PTSD and increased risk of chronic diseases such as diabetes and hypertension $[49,51]$. Finding employment opportunities can also be especially challenging due to the physical and mental impairments caused by past experiences of trauma and violence [48].

These forms of everyday structural violence leave refugees at higher risk of mental health disorders, and past exposure to trauma can leave refugees at higher risk of experiencing more post-migration stressors $[9,11 \bullet \bullet]$. Furthermore, post-migration stressors can sometimes end up having a larger impact on mental health than traumas experienced before and during migration $[11 \bullet \bullet]$. Studies have found that if refugees receive the proper mental health services but continue to face structural violence and deprivation due to barriers with employment, housing, social support, and other social determinants of health inequity, the effectiveness of those mental health services will be diminished [52]. Studies have also found that greater access to social services and interdisciplinary services, a more secure immigration status, and stable housing and employment can reduce the severity of PTSD symptoms [53].

These findings are very similar to those from the discourse on social determinants of health [54]. However, what distinguishes the refugee experience is the compounding and cyclic impact of trauma and violence. More studies are finding that individuals who experience trauma and violence are more likely to continue experiencing trauma and violence, and in some cases, even factors like education do not necessarily provide a protective role against the effects

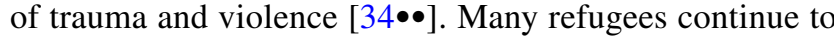
experience violence, if not more violence, after resettlement in the U.S, including witnessing someone being killed or severely injured, being beaten by someone other than a family member, domestic violence, intimate partner violence, and resettling in a poorer neighborhood with higher rates of community violence [55-57].

These cycles of trauma continue even past resettlement and down generational lines. Parental trauma has been associated with higher levels of mental health disorders and higher risks of abuse and neglect among children [56, 58, 59•]. Some studies have looked at the mediating roles of family functioning, maladaptive parenting, accumulation of family stressors, and severity of parental trauma, among others $[60,61 \bullet]$. However, the mechanisms of intergenerational trauma remain unclear. Many studies have tended to focus on the maternal transmission of molecular and epigenetic biomarkers down generations [62-65]. Researchers have examined patterns of DNA methylation and cortisol metabolism inherited by children of refugee mothers and have identified certain genes, such as $F K B P 5$, that may mediate 
intergenerational transmission among Holocaust survivors $[64,65]$. These studies may provide a foundational understanding of how the effects of trauma and violence can be transmitted in utero, but it is important to be wary of reducing the complexities of trauma and violence into a biological phenomenon.

Refugees are trapped in a cycle of trauma, driven by premigration and migration exposures, exacerbated by postmigration stressors, and reiterated by post-migration violence and intergenerational trauma. Clinical interventions must recognize this cycle before they can hope to attempt to break it.

\section{Models for Trauma-Informed Care}

Many studies have focused on exploring effective psychosocial therapies to help refugees combat PTSD, depression, anxiety, and other mental health disorders [53, 66]. More recently, Mental Health First Aid (MHFA) training programs have also been developed to increase mental health literacy among community members, decrease stigma, and provide tools for helping individuals in moments of crisis [67]. Many MHFA programs have had promising results, and some have found that bilingual MHFA programs augmented with cultural orientations can be more effective [ 52 , $68,69,70 \bullet$. However, few programs have yet been developed for refugees.

As more research has come out revealing the multidimensional impacts of trauma, more interventions are focusing on how to incorporate mental health services into a more comprehensive care continuum, one that attempts to address not only the psychological sequelae but all manifestations of trauma-material, physical, social, cultural, and so on. Many studies draw upon a social-ecological framework that incorporates a more holistic understanding of the effects of trauma at different time points before, during, and after migration, as well as at different levels of institutions and systems [52, 70•]. The challenge has been integrating such frameworks into a robust model for trauma-informed care.

One of the primary challenges with developing interventions comes from language and cultural barriers. Without proper communication and interpretation, not only is it challenging to conduct a thorough clinical assessment, but it also leaves refugees vulnerable to under-diagnosis and misdiagnosis, discouraging refugees from returning to the hospital to seek care again [71]. It is especially challenging to communicate about illness across cultures because each culture draws upon their own explanatory models, their own words, beliefs, and stigmas for illness, pain, and injury [72]. In the 1980s, the concept of "cultural idioms of distress" arose as a framework for better understanding how different people experience different forms of distress [73]. It was developed in response to earlier notions of "culture-bound syndromes" that categorized certain illnesses as specific to certain groups of people [72]. Cultural idioms of distress instead sought a more fluid understanding of illness. Since many studies have incorporated cultural idioms of distress into their methodology, and in 2013, the DSM-V also replaced "cultural bound syndromes" with "cultural concepts of distress." [71, 73-76] Many anthropological studies, for example, have looked at how conceptualizations of "thinking too much" differ among countries and sub-populations, in order to better understand varying perceptions of etiology, somatization, and treatment [77]. Most studies have focused more on gathering different expressions for distress, such as the Somali word buqsanaan, which translates to "loud noise" and refers to a "jammed mind," or the Rohingya word unniyashi lager, which refers to a feeling of suffocation, or the word waajara galip that Darfur refugees use to mean "pain in the heart." $[73,74,76]$ But there are many different expressions for distress and many different understandings of mental health, making it critical that clinicians and trained professional interpreters seek translation not just for semantic understanding but also for cultural understanding.

Cultural idioms of distress are only one part of a larger effort to build cultural competency, a term that first arose during the Civil Rights Movement to address racial and ethnic disparities [78]. Cultural competency is a core part of many interventions that work with refugee communities and seek to be culturally sensitive and culturally immersive [72]. In the past decade, however, there has been a shift away from cultural competency to structural competency, which recognizes that racial and ethnic disparities are not only due to cultural barriers, but also due to economic, sociopolitical, and systemic forces [79]. The discourse on structural competency, however, is still developing.

Building these competencies requires community partnerships to be leveraged as bridges for linguistic and cultural comprehension. In the academic space, community-based research has become the keystone of collaborative and equitable processes of knowledge creation [80]. In the clinical space, many interventions involve sharing resources with trusted community leaders, community health workers, and local volunteers, such as from a local place of worship, who can then relay resources to refugees in their community $[81 \bullet$, 82]. Various peer-to-peer educational programs, for example, have been developed to tap into community members who share common beliefs and values with refugee communities and who can then serve as "peer educators" within those communities [81 $\bullet, 83]$. These community partnerships help establish a line of communication that refugees can trust. 
Interdisciplinary collaborations are also critical for creating a network of continuous medical, social, and legal support for refugees. Within the hospital, community partnerships play an important role in achieving stronger care coordination between case managers, psychologists, and other members of the care team to connect refugees to health care services early on, help refugees navigate the health care system, and connect refugees to community resources [84-86]. Studies have shown that refugees with access to stable, uncrowded housing have improved mental health outcomes, indicating the importance of clinical interventions that address structural barriers and social determinants of health inequity [87]. The Refugee Wellbeing Project at the University of New Mexico, which matches refugee families with university student advocates who help refugees navigate community resources, has also found that its program helps lower levels of anxiety and depression among some groups of refugees [70•]. Outside the hospital, more and more medical-legal partnerships are also being formed to bring together clinicians and attorneys to advocate for their patients and clients [88]. Many medical students have established student-run asylum clinics that connect immigration attorneys with physicians, who volunteer to provide pro bono forensic evaluations documenting the sequelae of trauma and helping corroborate the narratives of asylum seekers [89]. Studies have shown that when asylum seekers receive a medical forensic evaluation by a physician, they are more likely to be granted political asylum [90]. In 2001, UC San Francisco also created the first Trauma Recovery Center (TRC) to provide survivors of trauma and violence with individual and group psychotherapy, medication management and support, case management, legal advocacy, and other services important for healing $[91 \bullet, 92]$. The TRC model recognizes that trauma and violence can incapacitate an individual from initially seeking help and instead uses an assertive outreach approach to bring survivors into the TRC [91•, 92]. The TRC in San Francisco has been shown to increase engagement in mental health services, increase access to care, and decrease health care costs [91•]. Since, more TRCs have been established across California, Ohio, and Illinois [92].

All of these components of building robust clinical interventions are important components of trauma-informed care. Trauma-informed systems involve realizing the impact of trauma, recognizing the histories of trauma, recognizing the signs and symptoms of trauma, responding to the effects of trauma, and resisting re-traumatization. [14•, $15,93,94]$ This is where clinicians can make the greatest impact. Trauma-informed care involves using structurally competent screening tools to assess for trauma and developing multidisciplinary interventions to connect refugees to medical, social, and legal services. It involves building an inclusive health care environment that is free of xenophobia and racism and that recognizes that some routine practices, such as breast examinations or imaging scans, can be potential triggers [15]. Most of all, it involves moving away from a focus on the pathology induced by trauma to the resiliency created by trauma. Many clinical and community interventions have been focusing on strengthening family and community bonds, using a strengths-based approach, and creating spaces for shared reflection and collective identity building $[35,80,91 \bullet, 95,96 \bullet]$. However, there are currently no clear sets of guidelines or protocols for creating a trauma-informed system. But it is critical that approaches to trauma-informed care are taught to staff and implemented in all health care and social care spaces, in order to create a health care system in which all refugees feel safe and welcome.

\section{Conclusion}

In 2015, the body of a 3-year-old Syrian boy washed up on the shores of a Turkish beach, and the photo captured the world [97]. The Syrian refugee crisis filled major headlines and brought the world's attention to mass humanitarian crises across the globe. Many countries have since opened their doors to refugees fleeing a past of persecution, violence, and victimization. However, past histories of trauma do not fade away upon resettlement. Refugees continue to experience high rates of physical and structural violence, exacerbating already existing effects of prior trauma and leaving refugees in a chronic state of vulnerability. The COVID-19 pandemic has only further exposed some of those inequities [12].

But there are many opportunities for intervention, from mental health screenings immediately upon arrival, to community-based support networks, to trauma-informed care in the hospital. If clinicians know how to recognize the physical and mental manifestations of trauma and violence, the hospital can serve as a nexus for connecting refugees to medical and social services and for keeping refugees engaged in a continuum of care. But more guidance is needed on how to develop effective trauma-informed protocols and programs for various refugee communities and individuals. What remains important is that refugees are not pathologized due to their past and continuing exposures to trauma but recognized for their potential and resiliency in the face of trauma.

\section{Declarations}

Conflict of Interest The authors declare that they have no conflict of interest.

Human and Animal Rights This article does not contain any studies with human or animal subjects performed by any of the authors. 


\section{References}

Papers of particular interest, published recently, have been highlighted as:

- Of importance

$\bullet$ Of major importance

1. United Nations High Commissioner for Refugees. Global trends: forced displacement in 2019. 2020. https://www.unhcr. org/5ee200e37.pdf. Accessed 24 Apr 2021.

2. United Nations High Commissioner for Refugees. Convention and protocol relating to the status of refugees. 2010. https:// www.unhcr.org/en-us/3b66c2aa10. Accessed 24 Apr 2021.

3. United States Department of State, United States Department of Homeland Security, United States Department of Health and Human Services. Report to congress on proposed refugee admissions for fiscal year 2021. 2020. https://www.state.gov/ reports/report-to-congress-on-proposed-refugee-admissionsfor-fy-2021/. Accessed 24 Apr 2021.

4. Batalova J, Hanna M, Levesque C. Frequently requested statistics on immigrants and immigration in the United States. In: Migration Information Source. Migration Policy Institute. 2021. https://www.migrationpolicy.org/article/frequentlyrequested-statistics-immigrants-and-immigration-unitedstates-2020\#refugees-asylum. Accessed 24 Apr 2021.

5. Abbas M, Aloudat T, Bartolomei J, Carballo M, DurieuxPaillard S, Gabus L, et al. Migrant and refugee populations: a public health and policy perspective on a continuing global crisis. Antimicrob Resist Infect Control. 2018;7:113. https:// doi.org/10.1186/s13756-018-0403-4.

6. Westfall NC, Nemeroff CB. The preeminence of early life trauma as a risk factor for worsened long-term health outcomes in women. Curr Psychiatry Rep. 2015;17(11):90. https://doi.org/10.1007/s11920-015-0625-6.

7. Betancourt TS, Newnham EA, Birman D, Lee R, Ellis BH, Layne CM. Comparing trauma exposure, mental health needs, and service utilization across clinical samples of refugee, immigrant, and U.S.-Origin Children. J Trauma Stress. 2017;30(3):209-18. https://doi.org/10.1002/jts.22186.

8. Abu Suhaiban H, Grasser LR, Javanbakht A. Mental health of refugees and torture survivors: a critical review of prevalence, predictors, and integrated care. Int J Environ Res Public Health. 2019;16(13):2309. https://doi.org/10.3390/ijerph1613 2309. This literature review reinforces the importance of connecting refugees to mental health services as early as possible.

9. Kim I. Beyond trauma: post-resettlement factors and mental health outcomes among Latino and Asian refugees in the United States. J Immigr Minor Health. 2016;18(4):740-8. https://doi. org/10.1007/s10903-015-0251-8.

10. Yun K, Fuentes-Afflick E, Desai MM. Prevalence of chronic disease and insurance coverage among refugees in the United States. J Immigr Minor Health. 2012;14(6):933-40. https://doi. org/10.1007/s10903-012-9618-2.

11.• Hou WK, Liu H, Liang L, Ho J, Kim H, Seong E, et al. Everyday life experiences and mental health among conflict-affected forced migrants: a meta-analysis. J Affect Disord. 2020;264:50 68. https://doi.org/10.1016/j.jad.2019.11.165. This meta-analysis found that among refugees, post-migration violence and stressors could have a stronger impact on mental health than pre-migration.

12. Shadmi E, Chen Y, Dourado I, Faran-Perach I, Furler J, Hangoma P, et al. Health equity and COVID-19: global perspectives.
Int J Equity Health. 2020;19(1):104. https://doi.org/10.1186/ s12939-020-01218-z.

13. Refugee Processing Center. Refugee admissions report as of March 31, 2021. 2021. https://www.wrapsnet.org/admissionsand-arrivals/. Accessed 24 Apr 2021.

14. Miller KK, Brown CR, Shramko M, Svetaz MV. Applying trauma-informed practices to the care of refugee and immigrant youth: 10 clinical pearls. Children. 2019;6(8). https://doi.org/10. 3390/children6080094. This article reviews some of the applications of trauma-informed care for refugee youth and their families. There are not many studies on trauma-informed care for refugees.

15. Roberts SJ, Chandler GE, Kalmakis K. A model for traumainformed primary care. J Am Assoc Nurse Pract. 2019;31(2). https://doi.org/10.1097/JXX.0000000000000116.

16.• LeMaster JW, Broadbridge CL, Lumley MA, Arnetz JE, Arfken $\mathrm{C}$, Fetters MD, et al. Acculturation and post-migration psychological symptoms among Iraqi refugees: a path analysis. Am J Orthopsychiatry. 2018;88(1):38-47. https://doi.org/10.1037/ ort0000240. This longitudinal study of Iraqi refugees found that post-migration violence and stressors predicted worse outcomes 1 year after arrival in the U.S. This study also reinforces a 2015 study that found that delayed access to mental health services after resettlement can increase risk of mental health disorders.

17. Sigvardsdotter E, Malm A, Tinghög P, Vaez M, Saboonchi F. Refugee trauma measurement: a review of existing checklists. Public Health Rev. 2016;37(1):10. https://doi.org/10.1186/ s40985-016-0024-5.

18. Mollica RF, Caspi-Yavin Y, Bollini P, Truong T, Tor S, Lavelle J. The Harvard Trauma Questionnaire: validating a cross-cultural instrument for measuring torture, trauma, and posttraumatic stress disorder in Indochinese refugees. J Nerv Ment Dis. 1992;180(2).

19. Hollifield M, Verbillis-Kolp S, Farmer B, Toolson EC, Woldehaimanot T, Yamazaki J, et al. The Refugee Health Screener-15 (RHS-15): development and validation of an instrument for anxiety, depression, and PTSD in refugees. Gen Hosp Psychiatry. 2013;35(2):202-9. https://doi.org/10.1016/j.genhosppsych.2012. 12.002 .

20. Kim E, Yun M, Jun JY, Park W-S. Pre-migration trauma, repatriation experiences, and PTSD among North Korean refugees. J Immigr Minor Health. 2019;21(3):466-72. https://doi.org/10. 1007/s10903-018-0742-5.

21. Mhlongo MD, Tomita A, Thela L, Maharaj V, Burns JK. Sexual trauma and post-traumatic stress among African female refugees and migrants in South Africa. S Afr J Psychiatry. 2018;24:1208. https://doi.org/10.4102/sajpsychiatry.v24.i0.1208.

22. Ainamani HE, Elbert T, Olema DK, Hecker T. Gender differences in response to war-related trauma and posttraumatic stress disorder - a study among the Congolese refugees in Uganda. BMC Psychiatry. 2020;20(1):17. https://doi.org/10.1186/ s12888-019-2420-0.

23. Riley A, Varner A, Ventevogel P, Taimur Hasan MM, WeltonMitchell C. Daily stressors, trauma exposure, and mental health among stateless Rohingya refugees in Bangladesh. Transcult Psychiatry. 2017;54(3):304-31.

24. Khan S, Haque S. Trauma, mental health, and everyday functioning among Rohingya refugee people living in short- and long-term resettlements. Soc Psychiatry Psychiatr Epidemiol. 2021;56(3):497-512. https://doi.org/10.1007/ s00127-020-01962-1.

25. Acarturk C, Cetinkaya M, Senay I, Gulen B, Aker T, Hinton D. Prevalence and predictors of posttraumatic stress and depression symptoms among Syrian refugees in a refugee camp. J Nerv 
Ment Dis. 2018;206(1):40-5. https://doi.org/10.1097/NMD. 0000000000000693.

26. Sudhinaraset M, Cabanting N, Ramos M. The health profile of newly-arrived refugee women and girls and the role of region of origin: using a population-based dataset in California between 2013 and 2017. Int J Equity Health. 2019;18(1):158. https://doi. org/10.1186/s12939-019-1066-3.

27. Gould LA, Agnich LE. Exploring the relationship between gender violence and state failure: a cross-national comparison. Violence Against Women. 2016;22(11):1343-70. https://doi.org/ $10.1177 / 1077801215624790$.

28. Aguirre NG, Milewski AR, Shin J, Ottenheimer D. Gender-based violence experienced by women seeking asylum in the United State: a lifetime of multiple traumas inflicted by multiple perpetrators. J Forensic Leg Med. 2020;72: 101959. https://doi.org/ 10.1016/j.jflm.2020.101959.

29. Khan NZ, Shilpi AB, Sultana R, Sarker S, Razia S, Roy B, et al. Displaced Rohingya children at high risk for mental health problems: findings from refugee camps within Bangladesh. Child Care Health Dev. 2018;45:28-35. https://doi.org/10.1111/cch. 12623.

30. Cummings EM, Merrilees CE, Taylor LK, Mondi CF. Developmental and social-ecological perspectives on children, political violence, and armed conflict. Dev Psychopathol. 2017;29(1):110. https://doi.org/10.1017/S0954579416001061.

31. Opaas M, Varvin S. Relationships of childhood adverse experiences with mental health and quality of life at treatment start for adult refugees traumatized by pre-flight experiences of war and human rights violations. J Nerv Ment Dis. 2015;203(9):684-95. https://doi.org/10.1097/NMD.0000000000000330.

32. Schlaudt VA, Bosson R, Williams MT, German B, Hooper LM, Frazier V, et al. Traumatic experiences and mental health risk for refugees. Int J Environ Res Public Health. 2020;17(6):1943. https://doi.org/10.3390/ijerph17061943.

33. Schweitzer RD, Vromans L, Brough M, Asic-Kobe M, CorreaVelez I, Murray K, et al. Recently resettled refugee womenat-risk in Australia evidence high levels of psychiatric symptoms: individual, trauma and post-migration factors predict outcomes. BMC Med. 2018;16(1):149. https://doi.org/10.1186/ s12916-018-1143-2.

34.•• Sengoelge M, Johnson-Singh CM, Mittendorfer-Rutz E, Vaez M, Saboonchi F. Identifying subgroups of refugees from Syria resettled in Sweden based on multiple trauma exposures: a latent class analysis of trauma history and mental health outcomes. J Psychosom Res. 2019;125: 109814. https://doi.org/10.1016/j. jpsychores.2019.109814. This study of Syrian refugees resettled in Sweden found that exposure to trauma and violence can be a predictor for future trauma and violence. The study also found that education does not necessarily provide a protective.

35. Liebling H, Barrett H, Artz L. South Sudanese refugee survivors of sexual and gender-based violence and torture: health and justice service responses in Northern Uganda. Int J Environ Res Public Health. 2020;17(5). https://doi.org/10.3390/ijerph1705 1685.

36. Hossain M, Pearson RJ, McAlpine A, Bacchus LJ, Spangaro $\mathrm{J}$, Muthuri S, et al. Gender-based violence and its association with mental health among Somali women in a Kenyan refugee camp: a latent class analysis. J Epidemiol Community Health. 2020;75(4):327-34. https://doi.org/10.1136/jech-2020-214086.

37. Lalla AT, Ginsbach KF, Penney N, Shamsudin A, Oka R. Exploring sources of insecurity for Ethiopian Oromo and Somali women who have given birth in Kakuma Refugee Camp: A Qualitative Study. PLoS Med. 2020;17(3): e1003066. https:// doi.org/10.1371/journal.pmed.1003066.
38. McAlpine A, Hossain M, Zimmerman C. Sex trafficking and sexual exploitation in settings affected by armed conflicts in Africa, Asia and the Middle East: systematic review. BMC Int Health Hum Rights. 2016;16(1):34. https://doi.org/10.1186/ s12914-016-0107-x.

39. Obertová Z, Cattaneo C. Child trafficking and the European migration crisis: the role of forensic practitioners. Forensic Sci Int. 2018;282:46-59. https://doi.org/10.1016/j.forsciint.2017.10. 036. This article helps identify the prevalence of child trafficking during and after migration. It is challenging to gather data on human trafficking among refugees.

40. Bermudez LG, Parks L, Meyer SR, Muhorakeye L, Stark L. Safety, trust, and disclosure: a qualitative examination of violence against refugee adolescents in Kiziba Camp, Rwanda. Soc Sci Med. 2018;200:83-91. https://doi.org/10.1016/j.socscimed. 2018.01.018.

41. Peck JL, Meadows-Oliver M, Hays SM, Maaks DG. White paper: recognizing child trafficking as a critical emerging health threat. J Pediatr Health Care. 2020. https://doi.org/10.1016/j. pedhc.2020.01.005. This article identifies refugee status as a risk factor for child trafficking. It is challenging to gather data on human trafficking among refugees.

42. Hachey LM, Phillippi JC. Identification and management of human trafficking victims in the emergency department. Adv Emerg Nurs J. 2017;39(1):31-51. https://doi.org/10.1097/TME. 0000000000000138.

43. Horyniak D, Melo JS, Farrell RM, Ojeda VD, Strathdee SA. Epidemiology of substance use among forced migrants: a global systematic review. PLoS ONE. 2016;11(7): e0159134. https:// doi.org/10.1371/journal.pone.0159134.

44. Mahmood HN, Ibrahim H, Goessmann K, Ismail AA, Neuner F. Post-traumatic stress disorder and depression among Syrian refugees residing in the Kurdistan region of Iraq. Confl Health. 2019;13:51. https://doi.org/10.1186/s13031-019-0238-5.

45. Fino E, Mema D, Russo PM. War trauma exposed refugees and posttraumatic stress disorder: the moderating role of trait resilience. J Psychosom Res. 2020;129: 109905. https://doi.org/10. 1016/j.jpsychores.2019.109905.

46. Chan EYY, Chiu CP, Chan GKW. Medical and health risks associated with communicable diseases of Rohingya refugees in Bangladesh 2017. Int J Infect Dis. 2018;68:39-43. https://doi. org/10.1016/j.ijid.2018.01.001.

47. Baranowski KA, Moses MH, Sundri J. Supporting asylum seekers: clinician experiences of documenting human rights violations through forensic psychological evaluation. J Trauma Stress. 2018;31(3):391-400. https://doi.org/10.1002/jts.22288.

48. Hess JM, Isakson BL, Amer S, Ndaheba E, Baca B, Goodkind JR. Refugee mental health and healing: understanding the impact of policies of rapid economic self-sufficiency and the importance of meaningful work. J Int Migr Integr. 2019;20(3):769-86. https://doi.org/10.1007/s12134-018-0628-3.

49. Hunter K, Knettel B, Reisinger D, Ganapathy P, Lian T, Wong $\mathrm{J}$, et al. Examining health care access for refugee children and families in the North Carolina triangle area. N C Med J. 2020;81(6):348. https://doi.org/10.18043/ncm.81.6.348.

50. Gillespie S, Cardeli E, Sideridis G, Issa O, Ellis BH. Residential mobility, mental health, and community violence exposure among Somali refugees and immigrants in North America. Health Place. 2020;65: 102419. https://doi.org/10.1016/j.healt hplace.2020.102419.

51. Golub N, Seplaki C, Stockman D, Thevenet-Morrison K, Fernandez D, Fisher S. Impact of length of residence in the united states on risk of diabetes and hypertension in resettled refugees. J Immigr Minor Health. 2018;20(2):296-306. https://doi.org/10. 1007/s10903-017-0636-y. 
52. Miller KE, Rasmussen A. The mental health of civilians displaced by armed conflict: an ecological model of refugee distress. Epidemiol Psychiatr Sci. 2017;26(2):129-38. https://doi. org/10.1017/S2045796016000172.

53. Kashyap S, Page AC, Joscelyne A. Post-migration treatment targets associated with reductions in depression and PTSD among survivors of torture seeking asylum in the USA. Psychiatry Res. 2019;271:565-72. https://doi.org/10.1016/j.psychres.2018.12. 047.

54. Hynie M. The social determinants of refugee mental health in the post-migration context: a critical review. Can J Psychiatry. 2018;63(5):297-303. https://doi.org/10.1177/0706743717 746666.

55. Salhi C, Scoglio AAJ, Ellis H, Issa O, Lincoln A. The relationship of pre- and post-resettlement violence exposure to mental health among refugees: a multi-site panel survey of Somalis in the US and Canada. Soc Psychiatry Psychiatr Epidemiol. 2021. https://doi.org/10.1007/s00127-020-02010-8.

56. Panter-Brick C, Eggerman M. Anthropology and global mental health: depth, breadth, and relevance. In: White RG, Jain S, Orr DMR, Read UM, editors. The Palgrave Handbook of Sociocultural Perspectives on Global Mental Health. London: Palgrave Macmillan UK; 2017. p. 383-401.

57. Wachter K, Cook Heffron L, Dalpe J. "Back home you just go talk to the family": the role of family among women who seek help for intimate partner violence pre- and postresettlement to the United States. J Interpers Violence. 2019. https://doi.org/10. $1177 / 0886260519835861$

58. Sangalang CC, Vang C. Intergenerational trauma in refugee families: a systematic review. J Immigr Minor Health. 2017;19(3):745-54. https://doi.org/10.1007/s10903-016-0499-7.

59.• Hoffman SJ, Vukovich MM, Gewirtz AH, Fulkerson JA, Robertson CL, Gaugler JE. Mechanisms explaining the relationship between maternal torture exposure and youth adjustment in resettled refugees: a pilot examination of generational trauma through moderated mediation. J Immigr Minor Health. 2020;22(6):1232-9. https://doi.org/10.1007/s10903-020-01052z. This study of Karen refugees resettled in the U.S. adds to the growing literature on intergenerational trauma among refugees.

60. Sangalang CC, Jager J, Harachi TW. Effects of maternal traumatic distress on family functioning and child mental health: an examination of Southeast Asian refugee families in the U.S. Soc Sci Med. 2017;184:178-86. https://doi.org/10.1016/j.socscimed. 2017.04.032.

61.• Flanagan N, Travers A, Vallières F, Hansen M, Halpin R, Sheaf $\mathrm{G}$, et al. Crossing borders: a systematic review identifying potential mechanisms of intergenerational trauma transmission in asylum-seeking and refugee families. Eur J Psychotraumatol. 2020;11(1):1790283. https://doi.org/10.1080/20008198.2020. 1790283. This systematic review highlights some of the possible mechanisms driving intergenerational transmission of trauma in refugee families.

62. Jawaid A, Roszkowski M, Mansuy IM. Transgenerational epigenetics of traumatic stress. Prog Mol Biol Transl Sci. 2018;158:273-98. https://doi.org/10.1016/bs.pmbts.2018.03. 003.

63. Yehuda R, Lehrner A. Intergenerational transmission of trauma effects: putative role of epigenetic mechanisms. World Psychiatry. 2018;17(3):243-57. https://doi.org/10.1002/wps.20568.

64. Javanbakht A, Stenson A, Nugent N, Smith A, Rosenberg D, Jovanovic $\mathrm{T}$. Biological and environmental factors affecting risk and resilience among syrian refugee children. J Psychiatr Brain Sci. 2021;6: e210003. https://doi.org/10.20900/jpbs.20210003.

65 Dashorst P, Mooren TM, Kleber RJ, de Jong PJ, Huntjens RJC. Intergenerational consequences of the Holocaust on offspring mental health: a systematic review of associated factors and mechanisms. Eur J Psychotraumatol. 2019;10(1):1654065. https://doi.org/10.1080/20008198.2019.1654065.

66. Nosè M, Ballette F, Bighelli I, Turrini G, Purgato M, Tol W, et al. Psychosocial interventions for post-traumatic stress disorder in refugees and asylum seekers resettled in high-income countries: systematic review and meta-analysis. PLoS ONE. 2017;12(2): e0171030. https://doi.org/10.1371/journal.pone. 0171030.

67. Kitchener BA, Jorm AF. Mental health first aid training for the public: evaluation of effects on knowledge, attitudes and helping behavior. BMC Psychiatry. 2002;2:10. https://doi.org/10.1186/ 1471-244x-2-10.

68. Morgan AJ, Ross A, Reavley NJ. Systematic review and metaanalysis of Mental Health First Aid training: effects on knowledge, stigma, and helping behaviour. PLoS ONE. 2018;13(5): e0197102. https://doi.org/10.1371/journal.pone.0197102.

69.• Gurung A, Subedi P, Zhang M, Li C, Kelly T, Kim C, et al. Culturally-appropriate orientation increases the effectiveness of mental health first aid training for Bhutanese refugees: results from a multi-state program evaluation. J Immigr Minor Health. 2020;22(5):957-64. https://doi.org/10.1007/s10903-020-009868. This study found promising results from a Mental Health First Aid program developed for Bhutanese refugees across 17 cities in 8 states across the U.S.

70. Goodkind JR, Bybee D, Hess JM, Amer S, Ndayisenga M, Greene RN, et al. Randomized controlled trial of a multilevel intervention to address social determinants of refugee mental health. Am J Community Psychol. 2020;65(3-4):272-89. https:// doi.org/10.1002/ajcp.12418. This study found that the Refugee Well-being Project at the University of New Mexico helped lower levels of anxiety and depression among some refugee groups.

71. Raghavan SS. Cultural considerations in the assessment of survivors of torture. J Immigr Minor Health. 2019;21(3):586-95. https://doi.org/10.1007/s10903-018-0787-5.

72. Morrison SD. Immigrant and refugee explanatory models of chronic disease. N C Med J. 2019;80(2):113. https://doi.org/10. 18043/ncm.80.2.113.

73. Kaiser BN, Jo WL. Culture-bound syndromes, idioms of distress, and cultural concepts of distress: new directions for an old concept in psychological anthropology. Transcult Psychiatry. 2019;56(4):589-98. https://doi.org/10.1177/1363461519862708.

74. Im H, Ferguson A, Hunter M. Cultural translation of refugee trauma: cultural idioms of distress among Somali refugees in displacement. Transcult Psychiatry. 2017;54(5-6):626-52. https:// doi.org/10.1177/1363461517744989.

75. Alemi Q, Weller SC, Montgomery S, James S. Afghan refugee explanatory models of depression: exploring core cultural beliefs and gender variations. Med Anthropol Q. 2017;31(2):177-97. https://doi.org/10.1111/maq.12296.

76. Tay AK, Riley A, Islam R, Welton-Mitchell C, Duchesne B, Waters V, et al. The culture, mental health and psychosocial wellbeing of Rohingya refugees: a systematic review. Epidemiol Psychiatr Sci. 2019;28(5):489-94. https://doi.org/10.1017/S2045 796019000192.

77. Backe EL, Bosire EN, Kim AW, Mendenhall E. "Thinking too much": a systematic review of the idiom of distress in Sub-Saharan Africa. Cult Med Psychiatry. 2021. https://doi.org/10.1007/ s11013-020-09697-z.

78. Bourgois P, Holmes SM, Sue K, Quesada J. Structural vulnerability: operationalizing the concept to address health disparities in clinical care. Acad Med. 2017;92(3):299-307. https://doi.org/ 10.1097/ACM.0000000000001294.

79. Metzl JM, Hansen H. Structural competency: theorizing a new medical engagement with stigma and inequality. Soc Sci Med. 
2014;103:126-33. https://doi.org/10.1016/j.socscimed.2013.06. 032.

80. Israel BA, Schulz AJ, Parker EA, Becker AB. Review of community-based research: assessing partnership approaches to improve public health. Annu Rev Public Health. 1998;19(1):173-202. https://doi.org/10.1146/annurev.publhealth.19.1.173.

81. Chaudhary A, Dosto N, Hill R, Lehmijoki-Gardner M, Sharp P, Daniel Hale W, et al. Community intervention for Syrian Refugees in Baltimore City: the Lay Health Educator Program at a Local Mosque. J Relig Health. 2019;58(5):1687-97. https://doi. org/10.1007/s10943-019-00893-9. This study found promising results from the Lay Health Educator Program, a peer-topeer education program developed for a local Syrian refugee population in Baltimore.

82. Meyerhoff J, Rohan KJ, Fondacaro KM. Suicide and suiciderelated behavior among Bhutanese refugees resettled in the United States. Asian Am J Psychol. 2018;9(4):270-83. https:// doi.org/10.1037/aap0000125.

83. Im H, Rosenberg R. Building social capital through a peer-led community health workshop: a pilot with the Bhutanese refugee community. J Community Health. 2016;41(3):509-17. https:// doi.org/10.1007/s10900-015-0124-z.

84. McMorrow S, Saksena J. Voices and views of Congolese refugee women: a qualitative exploration to inform health promotion and reduce inequities. Health Educ Behav. 2017;44(5):769-80. https://doi.org/10.1177/1090198117726572.

85. Shannon PJ, Vinson GA, Horn TL, Lennon E. Defining effective care coordination for mental health referrals of refugee populations in the United States. Ethnicity \& Health. 2018:1-19. https://doi.org/10.1080/13557858.2018.1547369.

86. Bager L, Hansen KS, Andersen CJ, Wang SJ. Does multidisciplinary rehabilitation of tortured refugees represent 'value-for-money'? A follow-up of a Danish case-study. BMC Health Serv Res. 2018;18(1):365. https://doi.org/10.1186/ s12913-018-3145-3.

87. Whitsett D, Sherman MF. Do resettlement variables predict psychiatric treatment outcomes in a sample of asylum-seeking survivors of torture? Int J Soc Psychiatry. 2017;63(8):674-85. https://doi.org/10.1177/0020764017727022.

88. League A, Donato KM, Sheth N, Selden E, Patel S, Cooper LB, Mendenhall E. A systematic review of medical-legal partnerships serving immigrant communities in the United States. J Immigr Minor Health. 2021;23(1):163-74. https://doi.org/10. 1007/s10903-020-01088-1.

89. Sharp MB, Milewski AR, Lamneck C, McKenzie K. Evaluating the impact of student-run asylum clinics in the US from 2016-2018. Health Hum Rights. 2019;21(2):309-23.
90. Lustig SL, Kureshi S, Delucchi KL, Iacopino V, Morse SC. Asylum grant rates following medical evaluations of maltreatment among political asylum applicants in the United States. J Immigr Minor Health. 2008;10(1):7-15. https://doi.org/10.1007/ s10903-007-9056-8.

91. Wiggall S, Boccellari A. The UC San Francisco Trauma Recovery Center Manual: a model for removing barriers to care and transforming services for survivors of violent crime. 2017. http:// traumarecoverycenter.org/wp-content/uploads/2020/04/TRCManual.pdf. Accessed 27 Aug 2021. This document describes the Trauma Recovery Center (TRC) model and how the TRC at UC San Francisco increased engagement in mental health services and reduced health care costs.

92. Baroni P. Supporting victims of violent crime using trauma recovery centers. Fed Sentencing Rep. 2017;30(2):103-7. https://doi.org/10.1525/fsr.2017.30.2.103.

93. SAMHSA's trauma and justice strategic initiative. SAMHSA's concept of trauma and guidance for a trauma-informed approach. https://ncsacw.samhsa.gov/userfiles/files/SAMHSA_Trauma. pdf. 2014. Accessed 24 Apr 2021.

94. Harris M, Fallot RD. Envisioning a trauma-informed service system: a vital paradigm shift. New Dir Ment Health Serv. 2001;2001(89):3-22. https://doi.org/10.1002/yd.23320018903.

95. Frounfelker RL, Mishra T, Dhesi S, Gautam B, Adhikari N, Betancourt TS. "We are all under the same roof": coping and meaning-making among older Bhutanese with a refugee life experience. Soc Sci Med. 2020;264: 113311. https://doi.org/10. 1016/j.socscimed.2020.113311.

96. Fabio M, Parker LD, Siddharth MB. Building on resiliencies of refugee families. Pediatr Clin N Am. 2019;66(3):655-67. https:// doi.org/10.1016/j.pcl.2019.02.011. This article highlights the importance of highlighting strengths and resiliencies among refugee youth and refugee families.

97. Slovic P, Västfjäll D, Erlandsson A, Gregory R. Iconic photographs and the ebb and flow of empathic response to humanitarian disasters. Proc Natl Acad Sci. 2017;114(4):640-4. https:// doi.org/10.1073/pnas.1613977114.

Publisher's Note Springer Nature remains neutral with regard to jurisdictional claims in published maps and institutional affiliations. 